\title{
Positive coaching psychology: A case study in the hybridization of positive psychology
}

\author{
Tim Lomas
}

\begin{abstract}
Positive psychology has fruitfully interacted with numerous other disciplines, creating new hybrid paradigms. One such instance involves coaching, which shares the field's focus on enhancing wellbeing and performance across life domains. As a result, there is considerable interest in exploring its interaction with positive psychology, and developing frameworks for their integration. To shed further light on their relationship, this paper explores four perspectives on the intersections and differences between these emerging fields. These include perspectives where: (a) the fields are essentially coterminous; (b) positive psychology encompasses coaching; (c) coaching encompasses positive psychology; and (d) the fields overlap but are not coterminous (the author's preferred perspective). More generally, the paper offers suggestions for how positive psychology can integrate with the various kinship fields in these processes of hybridisation.
\end{abstract}

Keywords: positive psychology, coaching, coaching psychology, theory

Acknowledgements: Thank you to students and colleagues at the University of East London, who have inspired and informed the analysis presented in this paper.

\section{Hybridizing Positive Psychology}

Since its inception, positive psychology (PP) has found itself becoming "twinned" with myriad conceptually-similar disciplines. Such twinning is usually indicated by the word "positive" being appended to the field in question. Thus, we find a panoply of hybrids such as "positive education" (Seligman, Ernst, Gillham, Reivich, \& Linkins, 2009), "positive health" (Seligman, 2008), "positive health psychology" (Schmidt, Raque-Bogdan, Piontkowski, \& Schaefer, 2011), "positive neuropsychology" (Randolph, 2015), "positive psychotherapy" (Seligman, Rashid, \& Parks, 2006), "positive clinical psychology" (Wood \& Tarrier, 2010), "positive organizational scholarship" (Cameron, Dutton, \& Quinn, 2003), "positive organizational behaviour" (Bakker \& Schaufeli, 2008), "positive social science" (Seligman, 1999), "positive social psychology" (Lomas, 2015b), "positive cross-cultural psychology" (Lomas, 2015a), "positive art therapy" (Wilkinson \& Chilton, 2013), "positive art" (Lomas, 2016), "positive sports psychology" (Salama-Younes, 2011), and, most relevantly here, "positive psychology coaching" (Passmore \& Oades, 2014).

How are we to regard such hybrids? One answer is that, in these cases, the prefix "positive" may serve a similar operational function as it does for PP itself. In that respect, Pawelski (2016a, 2016b) has shed valuable light on its functions. First, he offers a "descriptive" analysis of the way the term functioned in seminal documents in the founding of PP (Pawelski, 2016a). He identifies five main usages: (a) positive orientation ( $\mathrm{PP}^{\prime}$ 's basic direction, namely as complementary to the "negative" focus of mainstream psychology); (b) positive topography (its main areas of study, e.g., strengths); (c) positive target population (its beneficiaries, mainly non-clinical populations); (d) positive process (its approach for achieving desired outcomes, such as building good 
qualities); and (e) positive aim (its ultimate purpose or goal, namely providing an "empirical vision for understanding and cultivating wellbeing") (p.343). Then, in a "normative" analysis, Pawelski (2016b) suggests one inclusion criterion and five continuum criteria for identifying something as positive. The inclusion criterion is simply preference, in that a phenomenon is positive if its presence is preferred to its absence. Then, the continuum criteria indicate the "degree" of positivity, with positivity being a function of: (a) relative preference (the strength of the preference for it over something else); (b) sustainability across time (the longer-lasting the better); (c) sustainability across persons (the more popular the better); (d) sustainability across effects (the more positive knock-on effects, the better); and (e) sustainability across structures (the more scalable and transferable across contexts, the better).

It is possible that the term "positive" serves similar functions in the hybrid paradigms noted above. That is, fields such as education may have been inspired or encouraged by PP to develop a more positive orientation within their own context. However, that would not make the paradigms above "true" hybrids, but rather just parallel fields that have evolved towards a comparable ethos, towards their own "version" of PP. In that case, for instance, "positive education" would not mean that education has incorporated elements of PP, but rather has just followed its example in also developing a positive orientation within its own parameters. That might mean encouraging students to prioritise their academic strengths and skills, say, rather than fixing their academic weaknesses. We might refer to such examples as "nominal hybrids." Conversely, though, it is possible that such fields are genuine hybrids, in that a given field has a genuine and meaningful relationship with PP. This would mean that the field is drawing on ideas, theories, and practices that could be said to specifically pertain to PP, from resilience to gratitude. Thus, in that sense, "positive education" might include helping students to cultivate resilience and gratitude within an educational context (see e.g., L. Waters, 2014). In contrast to nominal hybrids, these "genuine" pairings could be referred to as "substantive hybrids." In these instances, rather than the prefix simply being "positive," one could argue that the prefix is actually "positive psychology," but that the labels for the fields are being elided in such a way that the term "psychology" has been concealed (thus "positive psychology education," say, is simply rendered as "positive education").

Questions around hybridisation are particularly intriguing where PP shares close conceptual and practical affinities with the field with which it is being paired. This is the case with the intersection between PP and coaching $(\mathrm{C})$ - and relatedly between PP and coaching psychology (CP) - where many scholars have noted their convergences (e.g., Biswas-Diener, 2010; Kauffman, 2006; Linley \& Harrington, 2007; Oades \& Passmore, 2014). For instance, Linley and Harrington (2007) suggest that both PP and C/CP: (1) are focused on the improvement of performance and well-being (as per Pawelski's (2016a) "positive orientation" and "positive aim"); (2) assume the possibility of optimal environmental conditions that can/do promote flourishing; and (c) are concerned with developing strengths and fostering their domino effects across all domains of a person's life. Such are the convergences that the conjoining of these fields - as per emergent paradigms such as "positive psychology coaching" (Passmore \& Oades, 2014, p.68) - constitutes a particularly interesting instance of hybridisation. However, the nature of their intersection remains a matter of debate. As such, exploring this intersection represents a fascinating case study for interrogating the hybridisation phenomenon more generally. Before considering the interaction between PP and C/CP though, it will help to consider the disciplines separately. For there is on-going debate as to what these fields are in themselves, which complicates the issue of understanding their interaction. 


\section{What is Positive Psychology?}

The status and identity of PP has always been somewhat opaque and contested. The field was initiated by Martin Seligman and colleagues in the late 1990s as a way of redressing a perceived "negative bias" in mainstream psychology (a move conceptualised by Pawelski (2016a) as PP's foundational "positive orientation"). Psychology as a whole was appraised as focusing primarily on disorder and dysfunction, with little attention paid - outside of certain pockets of scholarship, like humanistic psychology (Waterman, 2013) - to more "positive" aspects of human functioning, from flourishing to fulfilment. Hence the value of a drive to redress that imbalance, legitimising and encouraging exploration of these more "positive" phenomena (the "positive topography" in Pawelski's (2016a) analysis). For many people attracted to PP though, it was not a new field or speciality per se, but rather a "collective identity" unifying researchers interested in "the brighter sides of human nature" (Linley \& Joseph, 2004, p.4). According to that dominant perspective, PP is more an ethos, a way of "leaning towards" positive topics that is open to scholars and practitioners in established psychological fields, from clinical psychologists (e.g., Wood \& Tarrier, 2010) to neuroscientists (e.g., Urry et al., 2004). Alignment to this mind-set and identitynarrative served to unify disparate scholars already working on topics that are now regarded as falling within the purview of PP, such as positive emotions or psychological development.

More recently though, there have also been efforts to delineate PP as a specific discipline, endowing it with a distinct professional identity along the lines of specialities such as health or clinical psychology (Lomas \& Ivtzan, 2016a). Part of the impetus for this move comes from the community of postgraduate PP courses, whose numbers have greatly expanded in recent years, organically leading to some graduates and scholars self-identifying as PP "practitioners", and even as "positive psychologists" (though this label is contentious, not least since "psychologist" is usually a protected title in most jurisdictions). Two contrasting perspectives on the nature of $\mathrm{PP}$ are therefore emerging. The "ethos" perspective states that PP is potentially open to, and conducted by, scholars across all and any areas of psychology (and indeed other academic and professional fields, such as social work or nursing). For instance, a clinical psychologist interested in theories and practices pertaining to flourishing could be said to be aligned or engaged with PP, as for instance elucidated by Wood and Tarrier (2010) in their notion of "positive clinical psychology." Conversely, the "discipline" perspective views PP more as a distinct speciality, an identifiable branch of psychology - equivalent to clinical or counselling psychology, say whereby a scholar can specialise in PP (Lomas \& Ivtzan, 2016a). Of course, these two perspectives are not mutually exclusive. It is perfectly feasible for one scholar from a distinct branch of psychology (such as clinical psychology) to take a keen interest in PP, and so affiliate to it from an ethos perspective, and for another scholar to primarily view themselves as being situated within PP, and so to self-identify with it from a discipline perspective.

The issue of what PP is, exactly, nonetheless remains open. Beyond generalities such as focusing on "the brighter sides of human nature" (Linley \& Joseph, 2004, p.4), what are PP's defining characteristics? Various definitions of PP have been advanced over the years. For instance, Linley and Harrington (2007) define it as "the scientific study of optimal functioning, focusing on aspects of the human condition that lead to happiness, fulfilment, and flourishing" (p.13). A broader and more generic definition is offered by Lomas, Hefferon, and Ivtzan (2015), who position PP as the "science and practice of improving wellbeing" (p.1347). This latter definition aligns with Pawelski's (2016a) analysis of PP's "positive aim," in which he identifies $\mathrm{PP}^{\prime} \mathrm{s}$ "ultimate goal" as "providing an empirical vision for understanding and cultivating wellbeing" (p.343). In these operationalisations, wellbeing is an all-encompassing term, enfolding the various components identified by Linley and Harrington (2007) (e.g., optimal 
functioning, happiness, fulfilment, and flourishing). Indeed, wellbeing is increasingly favoured in academia as a broad, overarching, multidimensional term, incorporating all the ways in which a person might hope to do or be well (de Chavez, Backett-Milburn, Parry, \& Platt, 2005), including physical health (Larson, 1999), social relationships (Bourdieu, 1986), cognitive performance (Tang et al., 2007), and positive emotions (Diener, 2000). For instance, Pollard and Davidson (2001) define wellbeing as "a state of successful performance across the life course integrating physical, cognitive and social-emotional function" (p.10).

That said, in identifying PP as being focused on wellbeing, it is worth noting that wellbeing can be appraised in either deficit-based negative terms, or asset-based positive terms. With the former, wellbeing consists in the absence of some undesirable quality or process, whereas in the latter it means the presence of some desirable quality or process. An absence of a deficit does not necessarily entail the presence of an asset, i.e., that people are "flourishing." One of PP's foundational metaphors is of a continuum, from a nominal minus 10, through zero, and up to plus 10 (Keyes, 2002). On that metaphor, ameliorating deficits such as mental disorder constitutes bringing people up to "zero." That is hugely beneficial, as far as it goes. But one can still aim to move people into the positive integers. And it is that which PP focuses on, rather than ameliorating deficits (which was a common endeavour across "mainstream" psychology prior to the 1990s, and which retains a strong foothold in many areas, such as clinical psychology). The metaphor is not perfect; for instance, people can be simultaneously situated both in negative territory (e.g., diagnosed with mental illness) and positive territory (e.g., excelling in certain aspects of living) (Keyes, 2002). On the whole though, it is a useful schema for how PP sits in relation to other fields that are also concerned with wellbeing (but may do so from a more deficitbased perspective). As a final point, one prominent aspect of PP is the development of "positive psychology interventions" to improve wellbeing, such as gratitude exercises (Emmons \& McCullough, 2003), as well as applied initiatives geared towards the same end, such as public policy (Lomas, 2015b). Such activities are known under the generic rubric of "applied positive psychology" (APP). Collectively, PP and APP in this paper will be referred to using the acronym (A)PP.

\section{What is Coaching and Coaching Psychology?}

The roots of coaching stretch back at least as far as classical Greece, where elite athletes were coached by professional trainers (Allen, 2016). This foundational association with sporting endeavour continues to the present day (Palmer \& Whybrow, 2014), representing one of the first instances of coaching being studied in an academic context, namely through the work of Griffith (1926), a sports psychologist. Rather than viewing sports coaching as simply a form of instruction (i.e., regarding the physical skill required for a given sport), Griffith viewed the coach as also taking on the broader role of "teacher," whose duties included motivating and ministering to the psychological needs of athletes. In the following decades, this notion of coaching was embraced in other areas of activity, most notably business. Following work by scholars such as Gorby (1937), who suggested that coaching techniques could improve productivity and profitability, the 1940s onwards saw a burgeoning movement within occupational settings to hire coaches to help get the best out of employees. In the early years, such coaching often simply took the form of informal conversations, later followed by more systematically-organised and model-driven forms of coaching interaction (Kampa-Kokesch \& Anderson, 2001). This focus on business and occupational settings dominated the theory and practice of coaching for much of the 20th century. Then, in more recent decades, coaching has begun to be studied and deployed across myriad settings, outcomes, and endeavours, from health behaviours (Young et al., 2014) to family 
dynamics (Allen \& Huff, 2014).

Meanwhile, as those developments were taking place, the related concept of coaching psychology (CP) began to be identified, and to be differentiated from coaching. Back in the 1950s, Lawther (1951) was writing about the "psychology of coaching," and by the 1960s, the phrase "coaching psychology" had begun to appear in the literature (e.g., Gaylord, 1967). However, not until the 1990s did CP as a distinct sub-discipline began to emerge, principally through initiatives such as the foundation of the Coaching Psychology Unit at the University of Sydney, and the subsequent establishment of a similar unit at City University London. The emergence of $\mathrm{CP}$ was further strengthened through the launch of specialist journals, such as the International Coaching Psychology Review. As part of this emergence, scholars have sought to differentiate CP from coaching per se (Passmore \& Theeboom, 2016). One popular way is to present coaching as an applied activity, and CP as the psychological science of this activity. Thus, for instance, the International Coach Federation defines coaching as "partnering with clients in a thought provoking and creative process that inspires them to maximize their personal and professional potential." As an activity, this need make no explicit reference or recourse to psychological research or theory - although of course the coach may well choose to - but is in essence a process of human interaction between coach and client. CP might then be viewed as the scientific study and understanding of this process. In that sense, the domains of psychology which can inform this endeavour is very broad - from psychodynamic theories and methodology, to psychological perspectives on cognitive development. Here we can thus see a parallel with PP and APP, in that coaching can be regarded as equivalent to APP, and CP to PP. Collectively, both coaching and $\mathrm{CP}$ in this paper will be referred to using the acronym $\mathrm{C}(\mathrm{P})$.

In understanding $\mathrm{CP}$ as the science of coaching, however, several key questions emerge, which this paper seeks to explore, namely: (a) what is the scope and remit of $C(P)$, and (b), how do these differ from (A)PP? First, the nature of $\mathrm{C}(\mathrm{P})$ remains a matter of some debate. For instance, Passmore and Theeboom $(2016$, p.30) discuss attempts to fashion a working definition of coaching during a workshop in 2002 at the annual conference of the counselling psychology division of the British Psychological Society. Initially, Grant and Palmer (2002) proposed that coaching is focused on "enhancing performance in work and personal life domains with normal, non-clinical populations, underpinned by models of coaching in established therapeutic approaches." However, various critiques were made of that formulation, including in relation to the focus on "normal, non-clinical populations," since coaching techniques were starting to be offered in clinical domains, and also regarding the assumption that coaching only draws on therapeutic models. Consequently, an amended definition was proposed, stating that coaching is concerned with "enhancing wellbeing and performance in personal life and work domains, underpinned by models of coaching in established adult learning or psychological approaches." What is particularly interesting about this definition is that, apart from the reference to "models of coaching," it is highly similar to definitions of PP. So too are other definitions of C(P), such as Spence's (2007) explanation that coaching is "primarily concerned with human growth and change, based on the philosophical assumption that individuals have vast reservoirs of untapped potential within them and are naturally inclined towards developing that potential" (p.256). Thus, even while the nature of $(\mathrm{A}) \mathrm{PP}$ and $\mathrm{C}(\mathrm{P})$ themselves remains a matter of debate, the fields clearly share significant intersections and overlaps.

\section{Intersections and Overlaps}

So, (A)PP and C(P) evidently have numerous features in common (Linley \& Harrington, 2007). These include: (1) an applied focus on improving wellbeing and performance (per Pawelski's 
(2016a) "positive orientation" and "positive aim"); (2) an interest in engendering change across life settings, including personal life and in the workplace; (3) a humanistic emphasis on facilitating development, and helping people fulfil their potential (per Pawelski's "positive process"); and (4) an emphasis (albeit non-exclusively) on working with "normal" (i.e., nonclinical) populations (per Pawelski's "positive target population"). So, what are the differences between $(\mathrm{A}) \mathrm{PP}$ and $\mathrm{C}(\mathrm{P})$ ? Whenever this question is posed, it is usually in terms of comparing $\mathrm{PP}$ (rather than (A)PP more broadly) with coaching (rather than $\mathrm{C}(\mathrm{P})$ more broadly). In that respect, many scholars depict their interaction as a mutually beneficial partnership, in which each brings different skills and strengths to the table. In short, PP is often viewed as offering scientific theory and empirical rigour, and coaching as providing applied practices and proficiencies (Grant \& Cavanagh, 2007). For instance, Kauffman (2006) describes PP as the "science at the heart of coaching" (p.219), while Biswas-Diener (2010) positions coaching as "the natural choice for being the applied arm of positive psychology" (p.5). As such, the relationship is often discussed in terms of how PP can further the evidence base and theoretical underpinning that coaching may be seen to lack, while coaching can endow PP with the practical tools that it in turn is lacking (Oades \& Passmore, 2014).

However, this formulation would seem to challenge the role of $\mathrm{CP}$ as the science of coaching, and also to neglect the emergent praxis of APP. After all, describing PP as the "science at the heart of coaching" would appear to supplant the function of $\mathrm{CP}$ in this role. And yet there is evidently a flourishing paradigm of $\mathrm{CP}$, as illustrated above. Likewise, $\mathrm{PP}$ also has its own applied dimension in the form of APP. In this sense, the relationship between (A)PP and C $(\mathrm{P})$ is presently unclear. For instance, is coaching itself an example of APP? And if it is, one can argue that both PP and CP seek to scientifically study and understand the process of effective coaching. In that case, a range of options for the interaction of (A)PP and $\mathrm{C}(\mathrm{P})$ suggest themselves, including:

a) (A)PP and $\mathrm{C}(\mathrm{P})$ as coterminous: both $\mathrm{APP}$ and $\mathrm{C}$ are essentially forms of coaching, and $\mathrm{PP}$ and $\mathrm{CP}$ draw on an equally broad range of theory and research in studying them.

b) $\mathrm{C}(\mathrm{P})$ as a subset of (A)PP: (A)PP encompasses $\mathrm{C}(\mathrm{P})$, with APP including more forms of practice than $\mathrm{C}$, and $\mathrm{PP}$ including a wider range of theory and research than $\mathrm{CP}$.

c) (A)PP as a subset of $\mathrm{C}(\mathrm{P})$ : $\mathrm{C}(\mathrm{P})$ encompasses (A)PP, with $\mathrm{C}$ including more forms of practice than $\mathrm{APP}$, and $\mathrm{CP}$ including a wider range of theory and research than $\mathrm{PP}$.

d) (A)PP and $\mathrm{C}(\mathrm{P})$ as distinctive: both $(\mathrm{A}) \mathrm{PP}$ and $\mathrm{C}(\mathrm{P})$ draw on distinct, albeit potentially partially overlapping, forms of practice (in the case of APP and $\mathrm{C}$ ) and theory and research (in the case of PP and CP).

Further complicating this picture is the trend towards exploring a closer integration between (A)PP and C(P) (van Nieuwerburgh \& Tunariu, 2013). Thus we have seen the emergence of paradigms like "positive psychology coaching" (PPC). Passmore and Oades (2014) describe this as "coaching approaches that seek to improve short term well-being (i.e. hedonic well-being) and sustainable well-being (i.e. eudaimonic wellbeing) using evidence-based approaches from positive psychology and the science of well-being and enable the person to do this in an ongoing manner after coaching has completed" (p. 68). They propose that PPC is underpinned by four key theories that are often regarded as being the province of PP (cf. Pawelski's (2016a) "positive topography): strengths (Proctor, Maltby, \& Linley, 2011); broaden and build (Fredrickson, 2009), self-determination (Ryan \& Deci, 2000); and wellbeing generally (Seligman, 2012). There is evidence to support the view that the application of these theories influences some of the foci of 
coaching. For example, the identification and use of strengths in coaching settings can promote goal progress (Linley, Nielsen, Gillett, \& Biswas-Diener, 2010), flow (Jackson \& Csikszentmihalyi, 1999) and psychological capital (Luthans, Avolio, Avey, \& Norman, 2007).

As such, given the complexities of the potential relationship between (A)PP and $\mathrm{C}(\mathrm{P})$, as elucidated above, further deliberation and research are needed to help us better understand the interaction between (A)PP and $\mathrm{C}(\mathrm{P})$, thus facilitating more integrative approaches. Such forms of enquiry are particularly relevant given the emergence of courses such as the MSc in Applied Positive Psychology and Coaching Psychology at the University of East London. With this, and other similar initiatives, scholars and students in both arenas - (A)PP and $\mathrm{C}(\mathrm{P})$ - are beginning to look meaningfully at their interaction, and in the process help both fields develop and progress. To that end, this paper presents an analysis of several possible ways of conceptualizing their interaction.

\section{Querying Ownership}

The conventional view is that (A)PP brings theoretical models and empirical research to the relationship, while $\mathrm{C}(\mathrm{P})$ offers practical expertise and skills. However, for this view to hold, it would mean that PP has exclusive access to, or ownership of, scientific theory and research, to which CP itself cannot lay claim. Similarly, it would mean that coaching has exclusive access to, or ownership of, specific applied practices that "belong" to coaching, and to which APP cannot lay claim. However, neither of those arguments can be supported. Firstly, it is not the case that specific theories "belong" to PP. Consider the theory of self-determination (Ryan \& Deci, 2000). This is often cited as being among the trove of theoretical insights that PP brings to the interaction with coaching (Passmore \& Oades, 2014). However, Deci and Ryan (1980) had been developing this theory for decades before PP emerged on the scene. Moreover, Deci and Ryan themselves do not appear to strongly align with PP; at most they imply that PP would benefit from fully incorporating the implications of their theory (Deci \& Vansteenkiste, 2004). As such, it would be overweening for PP to claim self-determination theory as "one of its own." While PP has wholeheartedly embraced the theory (Ryan, Huta, \& Deci, 2013), that is not the same as "owning" it. Indeed, CP has likewise embraced the theory to its benefit (Spence \& Oades, 2011). Thus, selfdetermination is not owned by $\mathrm{PP}$, nor by $\mathrm{CP}$, but rather is harnessed by both.

Similarly, nor is it that specific practices "belong" to coaching, thus constituting the corpus of applied techniques that it supposedly brings to the (A)PP - $\mathrm{C}(\mathrm{P})$ intersection. Take the practice of mindfulness for instance - both as a skill/quality manifested by the coach, and as a skill/quality that they might encourage in their client. One might consider this an example of an applied technique that has been utilized within coaching (Passmore \& Marianetti, 2007). However, mindfulness was first harnessed in the West within clinical settings as a treatment for chronic pain (Kabat-Zinn, 1982). And it was initially developed as a psychospiritual practice within Buddhism around 2,500 years ago (Lomas, 2017). Thus, by no stretch of the imagination does mindfulness "belong" to coaching. Likewise, mindfulness has been harnessed by APP in applied settings that could not be construed as pertaining to coaching per se, such as in educational contexts (Ivtzan \& Lomas, 2016a). Again though, there is no way mindfulness could be regarded as a "positive psychology intervention." Thus, as with self-determination theory, mindfulness constitutes an applied practice (together with concomitant theoretical perspectives) that belongs neither to APP nor coaching, but has been profitably harnessed by both.

\section{Relationship Configurations}

As such, what we have is a vast corpus of psychological theories, evidence-bases, and applied 
practices - developed across psychology as a whole, and other allied disciplines - that belong neither to (A)PP nor $\mathrm{C}(\mathrm{P})$, but can be harnessed by both. Thus, both $(\mathrm{A}) \mathrm{PP}$ and $\mathrm{C}(\mathrm{P})$ can be seen as having theoretical/empirical dimensions (i.e., $\mathrm{PP}$ and $\mathrm{CP}$ ), and both have a realm of applied practice (i.e., APP and C). If that is the case, then how can we appraise the intersection between (A)PP and $\mathrm{C}(\mathrm{P})$ ? It seems that this relationship can be configured in one of four main ways - as alluded to above - depending on how generously and expansively one defines the fields.

The first way simply views (A)PP and $\mathrm{C}(\mathrm{P})$ as fundamentally coterminous, covering the same territory, as outlined in figure 1 below. From that stance, there is essentially nothing in $\mathrm{C}(\mathrm{P})$ that could not also be said to pertain to (A)PP, and vice versa. That is, as articulated above, (A)PP and $\mathrm{C}(\mathrm{P})$ share numerous aims and concerns, including promoting wellbeing and performance, and facilitating the fulfilment of potential. In that respect, both PP and CP can draw on an equally wide range of theory and research, while at the same time, APP would regarded as synonymous with coaching (in this view). In the interests of openness, this is not my view, with my preferred configuration being the fourth one, in which (A)PP and $\mathrm{C}(\mathrm{P})$ are overlapping but non-identical. Nevertheless, logically, (A)PP and $\mathrm{C}(\mathrm{P})$ as coterminous is one model of their interaction, to which some scholars and practitioners may be drawn. For instance, one could imagine this configuration appealing to someone who defines $\mathrm{C}(\mathrm{P})$ very broadly (so that every form of interaction in APP could be deemed a type of coaching, for instance), while also defining (A)PP somewhat narrowly (so that it excludes interactions that cannot be seen through a coaching prism, such as more systemic initiatives).

Figure 1. Interaction \# $1=(\mathrm{A}) \mathrm{PP} \& \mathrm{C}(\mathrm{P})$ as coterminous

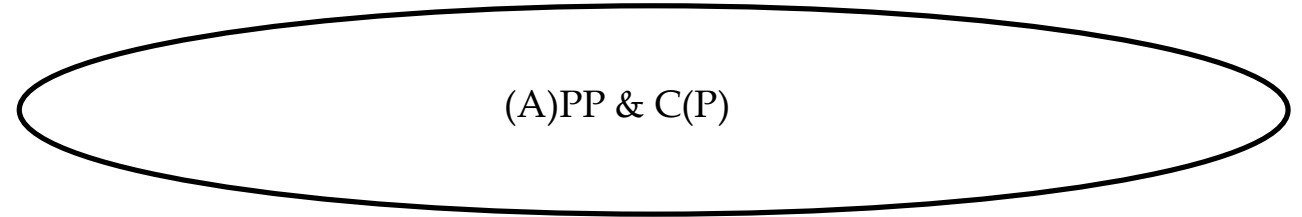

The second perspective takes a more expansive view of (A)PP, and positions $\mathrm{C}(\mathrm{P})$ as its subset, as outlined in figure 2 below. From that stance, although (A)PP and $\mathrm{C}(\mathrm{P})$ share numerous aims and concerns (e.g., promoting wellbeing and performance), $\mathrm{C}(\mathrm{P})$ is not the only means by which these can be achieved. Other examples include macro-level initiatives, such as the formation of public policy to promote wellbeing (Lomas, 2015). Thus, on this view, $\mathrm{C}(\mathrm{P})$ could be deemed a subset of the broader field of PP. In this case, one could imagine this configuration appealing to people who primarily affiliate to (A)PP, and have an expansive appreciation for the scope of the field, drawing its boundaries widely so that it intersects with fields ranging from nursing to politics. Then, if all coaching was viewed as pertaining to wellbeing in some way, one could see how $\mathrm{C}(\mathrm{P})$ would be positioned as just one element of a much broader field of $(\mathrm{A}) \mathrm{PP}$.

Figure 2. Interaction \# 2: (A)PP as encompassing $\mathrm{C}(\mathrm{P})$

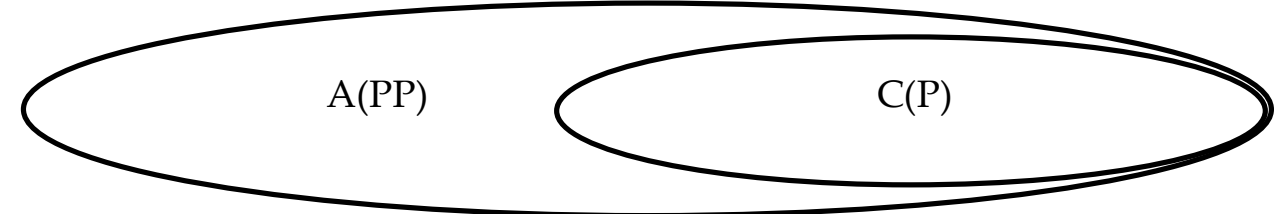

Conversely, the third perspective reverses the scope of the fields in the second perspective, taking 
a more expansive view of $\mathrm{C}(\mathrm{P})$, and positioning $(\mathrm{A}) \mathrm{PP}$ as its subset, as outlined in figure 3 below. For instance, whereas $\mathrm{C}(\mathrm{P})$ could be regarded as focusing on improving all aspects of life, (A)PP could be deemed as focusing on wellbeing in particular. Thus, on this view, (A)PP could be regarded as a subset of the broader field of $\mathrm{C}(\mathrm{P})$. In a mirror image of the second perspective, one could envisage this configuration appealing to those who primarily affiliate to $(\mathrm{C}) \mathrm{P}$, and have an expansive appreciation for the scope of the field, drawing its boundaries widely so that it not only pertains to wellbeing, but all aspects of functioning. Then, if such people have a relatively narrow view of (A)PP - conceptualising it as just involving theories and interventions relating to positive emotions, for instance - then one could see how this might be situated as one aspect of a wider paradigm of $\mathrm{C}(\mathrm{P})$.

Figure 3. Interaction \# 2: $\mathrm{C}(\mathrm{P})$ as encompassing $(\mathrm{A}) \mathrm{PP}$

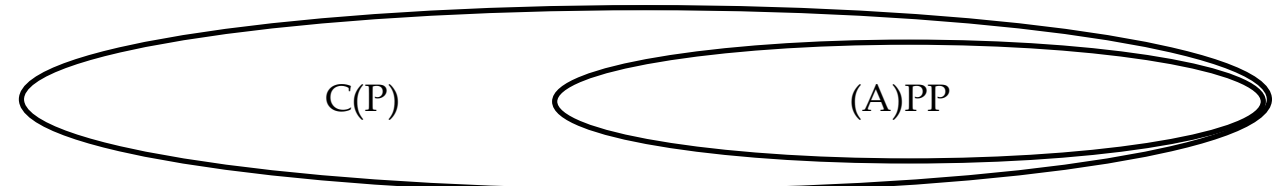

Finally, one could also configure the relationship whereby $(\mathrm{A}) \mathrm{PP}$ and $\mathrm{C}(\mathrm{P})$ constitute overlapping but not coterminous fields of endeavour. Here, $(\mathrm{A}) \mathrm{PP}$ and $\mathrm{C}(\mathrm{P})$ both have theoretical/empirical and applied dimensions in common. However, they also have aspects which pertain to only one of them. If, for example, one defines PP as the "science and practice of improving wellbeing" (Lomas et al., 2015, p.1347), this leaves open the possibility of identifying forms of coaching that do not directly pertain to wellbeing, but rather just to performance. For example, a person might receive coaching to better themselves at some discipline, such as job performance. While this activity may of course pertain to wellbeing - such as inducing flow (Csikszentmihalyi, 1990) - it does not necessarily. One might conceivably imagine a person improving while deriving no direct wellbeing benefits - such as experiences of pleasure, or health improvements - from doing so. In that respect, (A)PP and $\mathrm{C}(\mathrm{P})$ might constitute an overlapping Venn diagram, as shown in figure 4 below.

Figure 4. Interaction \# 4: (A)PP \& $\mathrm{C}(\mathrm{P})$ as overlapping

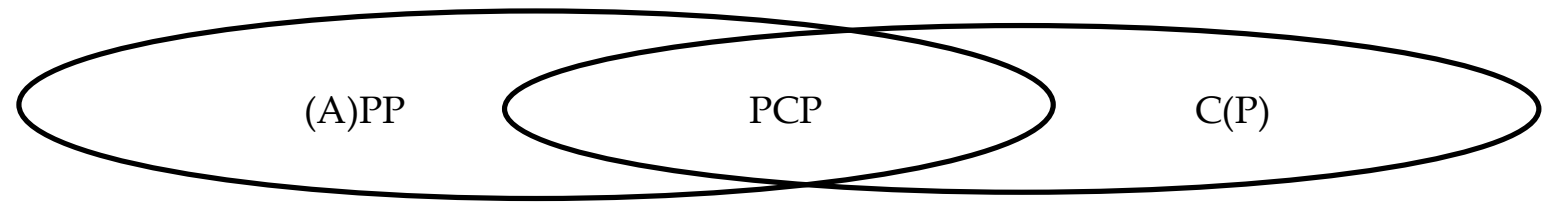

\section{Identifying Territorial Claims}

As noted above, this fourth configuration is my preferred one. So, staying with this perspective for a moment, figure 5 below offers a flow chart for identifying whether a given theory or practice pertains to either (A)PP, $\mathrm{C}(\mathrm{P})$, neither, or both - with the latter being an integrative paradigm referred to here as positive coaching psychology (PCP). The first question is whether "it" - the empirical outcomes, theoretical models, or applied practice in question - directly pertains to wellbeing (per Pawelski's (2016a) ultimate "positive aim" of PP). The qualifier "directly" is important here, albeit one that is difficult to definitively judge. That is, it's helpful to try to 
differentiate between phenomena that directly and indirectly pertain to wellbeing. After all, just about anything could be said to "indirectly" pertain to wellbeing, inasmuch as it is hard to conceive of something that does not affect wellbeing, however obliquely. To give a random example, honing memory skills through mnemonic techniques indirectly impacts wellbeing in various ways, from improved memory facilitating educational and occupational success, to being better able to recall positive experiences (T. Waters, 2014). As such, if we were to consider here phenomena that indirectly affect wellbeing, then all human endeavour might be regarded as within the purview of (A)PP. Thus, it would be prudent to at least attempt to only focus on phenomena that directly pertain to wellbeing, even if differentiating between direct and indirect is difficult in practice. This differentiation also means that it is possible to identify forms of $\mathrm{C}(\mathrm{P})$ that do not overlap with (A)PP, as alluded to in the paragraph above (e.g., forms of occupational coaching that do not directly focus on enhancing wellbeing).

Figure 5. Flow chart for differentiating between fields

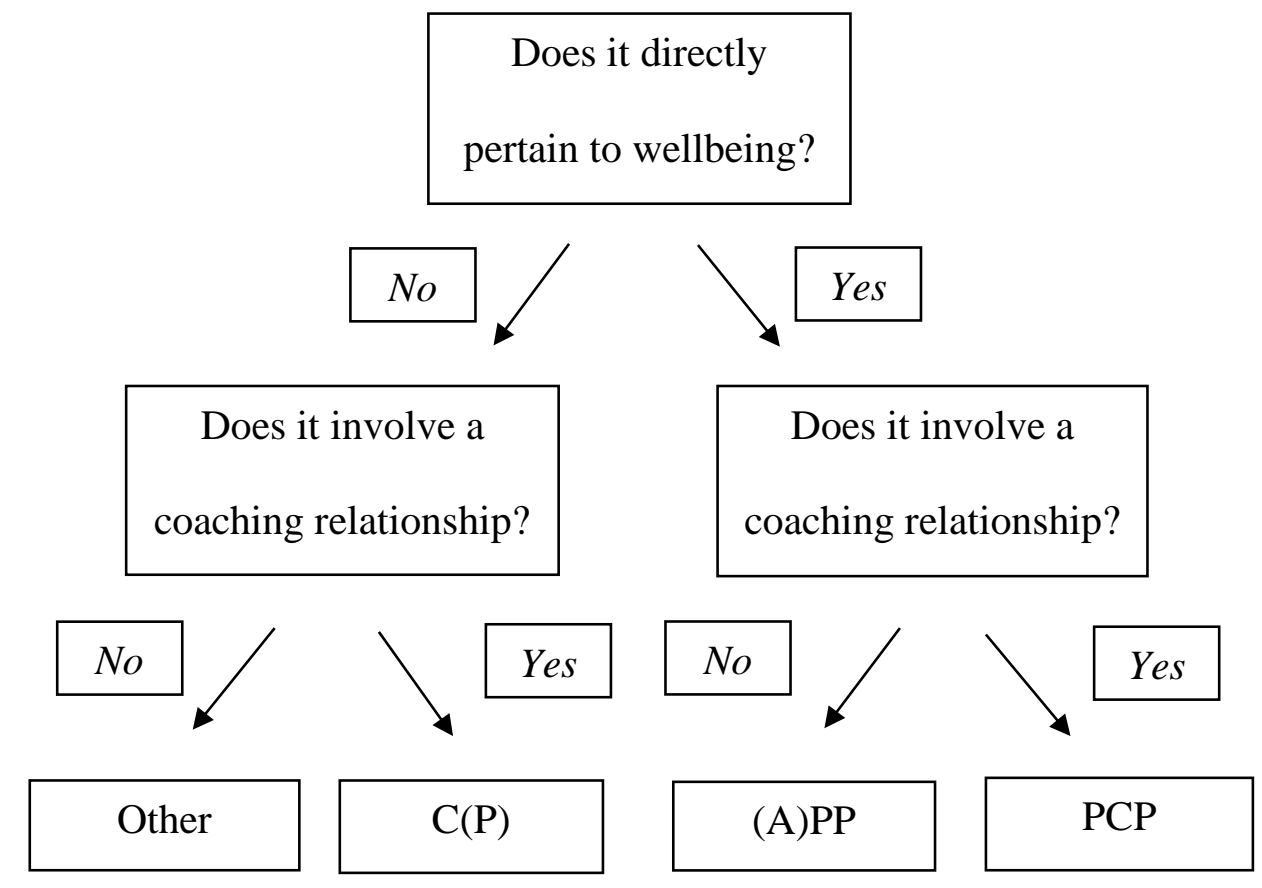

If it is ascertained that a given phenomenon (e.g., theory, applied practice) does not directly pertain to wellbeing, then it is not "within the scope" of (A)PP. (The phrase "within the scope" is felicitous here, and preferable to formulations such as "belonging to." As elucidated above, it is not the case that particular theories, concepts, or practices "belong" exclusively to (A)PP, nor indeed to any other academic field.) That being so, one can then ask whether the phenomenon involves a coaching relationship. Of course, there may be variation in how one chooses to define such a relationship, with the possibility of doing so more narrowly (e.g., limiting it to situations in which the participants self-identify as coach and client), or more widely (e.g., all manner of variations on that theme, such as mentoring or teaching). If the phenomenon does not involve such a relationship, then it falls within the scope of neither $(\mathrm{A}) \mathrm{PP}, \mathrm{C}(\mathrm{P})$, nor PCP. If it does, then it may represent a case of $\mathrm{C}(\mathrm{P})$ alone (i.e., an instance of $\mathrm{C}(\mathrm{P})$ that does not overlap with $(\mathrm{A}) \mathrm{PP})$. If the phenomenon does directly pertain to wellbeing, then once again, one can ask whether it features a coaching relationship. If not, then it falls within the scope of (A)PP alone (i.e., an instance of (A)PP that does not overlap with $\mathrm{C}(\mathrm{P})$ ), whereas if yes, then it represents an instance 
of PCP (i.e., where (A)PP and $\mathrm{C}(\mathrm{P})$ intersect). Thus, this chart offers an initial way of appraising the ways in which $(\mathrm{A}) \mathrm{PP}$ and $\mathrm{C}(\mathrm{P})$ overlap and yet also differ. It is hoped this articulation will be useful to proponents of $(\mathrm{A}) \mathrm{PP}$ and $\mathrm{C}(\mathrm{P})$ who are interested in exploring their integration over the coming years.

\section{Relevance to Hybridisation}

Moreover, this analysis may have broader relevance beyond the specific interaction of (A)PP and $\mathrm{C}(\mathrm{P})$. A key aim here was for this enquiry to serve as a case study for the myriad other PP hybrids, from "positive education" (Seligman et al., 2009) to "positive clinical psychology" (Wood \& Tarrier, 2010). That is not to suggest that in every hybrid, the dynamics will be the same as those identified above with respect to $(\mathrm{A}) \mathrm{PP}$ and $\mathrm{C}(\mathrm{P})$. Indeed, there may well be different forms of hybridisation. For instance, a distinction was made in the introduction between "nominal" and "substantive" hybrids. The former is when another field simply harnesses the prefix "positive" - perhaps influenced by PP's example - thereby developing a positive orientation within its own context. The latter is when a field has genuinely sought a meaningful integration with (A)PP (e.g., incorporating theories closely associated with PP). That said, this distinction does not mean one can definitively pigeon-hole the various hybrids: rather than viewing these two types as exclusive categories, it is perhaps more useful to see them as a continuum, involving greater or lesser degrees of integration with (A)PP. In any case, people may view a given paradigm in different ways - some seeing it more as a nominal hybrid, others as a substantive one - as I shall discuss further below. And then, even if there is general agreement over the type of hybrid, there may well be differences of opinion regarding its nature. All that is to say that the specifics of the analysis above - of the (A)PP - C(P) interaction - may not generalise to other hybrids. However, the principles of the analysis above may have broader relevance. So, with any hybrid, one might also usefully look at: (a) ideological diversity; (b) different relationship configurations; (c) issues of ownership; and (d) schematics for identifying territorial claims.

With (a), this refers to the likelihood that within any given field or paradigm, there will be a diversity of perspectives with regard to how it intersects with (A)PP. For instance, in their elucidation of "positive clinical psychology," Wood and Tarrier (2010) recommend that clinical psychology brings on board the commitment to positivity fostered by PP, while maintaining its concern with "negative" phenomena (i.e., mental illness), thus "integrat[ing] the study and fostering of positive and negative characteristics equally" (p.820); however, they also note that their colleagues may not be uniformly in favour of such integration, with some holding the view that "positive topics are not within the remit of clinical psychology." Such ideological diversity is to be expected, and even encouraged (on the view, as per Haidt, Rosenberg, and Hom (2003), that viewpoint diversity enriches fields and organisations). Thus, where hybrid paradigms do exist, it would be worth identifying varying perspectives on the nature of the integration. This could be through analyses like the one conducted here, or a myriad of other ways, from in-depth interviews with practitioners and stakeholders (see Bas and Firat (2017) in relation to "positive education"), to more extensive surveys of the field.

Such diversity then impacts upon (b), namely how the relationship between the two fields is configured. In relation to $(\mathrm{A}) \mathrm{PP}-\mathrm{C}(\mathrm{P})$, four alternatives were presented: $(1)(\mathrm{A}) \mathrm{PP}$ and $\mathrm{C}(\mathrm{P})$ as coterminous; (2) C(P) as a subset of (A)PP; (3) (A)PP as a subset of $\mathrm{C}(\mathrm{P})$; and (4) (A)PP and $\mathrm{C}(\mathrm{P})$ overlapping, but each also possessing distinctive features. It is likely that all hybrids could similarly develop a range of configuration models, which could variously attract proponents within the paradigm. For instance, it has been suggested here that, as per Pawelski (2016a), PP's overall aim is with improving "wellbeing." There are then interesting conceptual debates 
regarding the relationship between wellbeing and similarly overarching terms, such as health. For instance, de Chavez et al. (2005) argue that some scholars view wellbeing as a subset of a health, whereas for others, wellbeing is the broader term, with health being a subset (one focused on physical wellbeing specifically). As such, in relation to "positive health" (Seligman, 2008), one could imagine, (1) some scholars deeming (A)PP a subset of the broader domain of health (premised on wellbeing being a subset of health), (2) others arguing that health is a subset of (A)PP (based on wellbeing as the broader term), (3) yet others proposing various forms of overlap, and (4) still others not seeing an overlap at all (based on the idea that "positive health" is a nominal hybrid, rather than a substantive one). Seligman (2008) himself appears to endorse a version of (4), suggesting that "positive health" merely has "parallels" to (A)PP, in that it focuses on "[physical] health rather than illness" (just as PP focuses on mental health rather than mental illness) (p.3).

Third, with respect to (c), analyses of hybrid paradigms would likely enquire into issues around ownership. It was argued here that particular theories and practices could not be said to "belong" to (A)PP or C(P), but rather just "pertain" to them. Wood and Tarrier (2010) make a similar point with respect to "positive clinical psychology." For a start, so-called "positive characteristics," like resilience, are "causally implicated in the development of disorder, and buffer the impact of life events on distress" (pp.820-821); such topics and qualities are therefore highly germane to clinical psychology, regardless of these also being central to PP. Moreover, they argue that "no topic can be deemed as fundamentally "positive" or "negative"", since qualities that are deemed positive can, in their absence, be detrimental to wellbeing; thus, for instance, an inability to forgive can be maladaptive, which then brings the topic of forgiveness within the purview of clinical psychology. Indeed, in a similar vein, proponents of so-called "second wave" PP have suggested that it is difficult to categorically identify a given topic as positive or negative, since such appraisals are context dependent (Lomas \& Ivtzan, 2016b). With forgiveness, for example, while this is generally an adaptive process, McNulty and Fincham (2011) argue that this can, under certain contexts (e.g., on-going abusive relationships) be ultimately detrimental to wellbeing. Thus, within every hybrid paradigm, there are debates to be had around which topics or practices "belong" or "pertain" to either of the partner fields.

Finally, following on from (3), point (4) holds that it may be possible to develop rubrics for identifying "territorial claims" with respect to the fields that form the hybrid paradigms. Here, a flow chart was offered for differentiating between theories and practices that pertain to: (a) (A)PP alone, (b) C(P) alone, (c) both (A)PP and C(P) (labelled here as PCP), and (d) neither. In that case, the relevant questions determining the "flow" were "does it directly pertain to wellbeing?" (whereby a negative answer would take the phenomenon in question out of the purview of (A)PP), and "does it involve a coaching relationship?" (whereby a negative answer would take it out of the purview of $\mathrm{C}(\mathrm{P})$ ). One could imagine similar heuristics being created with respect to other hybrids. Take "positive education," for instance. In that case, the first question could remain operative (where a negative answer would take the phenomenon out of the purview of (A)PP), but the second question could be "does it pertain to educational settings?" (whereby a negative answer would take it out of the purview of education). In that case, there may well be: per (a), aspects of (A)PP that are not directly relevant to education (although that of course depends upon how widely one views the remit of education), such as topics relating to physical health; per (b), aspects of education that are not directly relevant to (A)PP (although that too depends upon how widely one views the remit of (A)PP), such as protocols around examinations and marking; per (c), topics that pertain to both (A)PP and education, and so fall do within the remit of "positive education," such as deployment of the strengths paradigm 
within the classroom (see e.g., White \& Waters, 2015); and per (d), phenomena related to neither (A)PP nor education.

\section{Conclusion}

The analysis here sheds light on the intersection between (A)PP and $\mathrm{C}(\mathrm{P})$, and moreover has broader relevance to the various hybrid paradigms that have emerged over recent years. In relation to the $(\mathrm{A}) \mathrm{PP}-\mathrm{C}(\mathrm{P})$ intersection specifically, the findings here challenged the conventional assumption that $\mathrm{PP}$ brings empirical science to the partnership while coaching provides practical expertise. Rather, I suggested that both (A)PP and $\mathrm{C}(\mathrm{P})$ draw on a common body of theories and practice, which as such, "belong" to neither field. I then set our four possible permutations for the interactions of the fields: $(1)(\mathrm{A}) \mathrm{PP}$ and $\mathrm{C}(\mathrm{P})$ as coterminous; $(2) \mathrm{C}(\mathrm{P})$ as a subset of (A)PP; (3) (A)PP as a subset of $\mathrm{C}(\mathrm{P})$; and (4) (A)PP and $\mathrm{C}(\mathrm{P})$ overlapping, but each also possessing distinctive features. I then noted my preference for the fourth configuration, and in that respect, presented a flow-chart that allows one to differentiate between theories/practices that pertain to: (a) (A)PP alone; (b) $\mathrm{C}(\mathrm{P})$ alone; (c) both (A)PP and $\mathrm{C}(\mathrm{P})$ (labelled here as $\mathrm{PCP}$ ); and (d) neither. I then argued that, while other hybrid paradigms may differently conceptualise the relationship between PP and the particular field, many of the same questions and principles applied in the analysis here will still be relevant. These include issues around: (a) ideological diversity; (b) different relationship configurations; (c) ownership; and (d) identifying territorial claims. It is hoped that this analysis will be useful to scholars and practitioners in (A)PP and C $(\mathrm{P})$, and in all the fields with which (A)PP is entering hybrid relationships, thereby allowing such hybridisation to further develop and prosper over the coming years and decades.

\section{Authors}

Tim Lomas

University of East London

t.lomas@uel.ac.uk

\section{Publishing Timeline}

Received 7 December 2019

Accepted 20 April 2020

Published 1 June 2020

\section{References}

Allen, K. (2016). Theory, research, and practical guidelines for family life coaching. Netherlands: Springer.

Allen, K., \& Huff, N. L. (2014). Family coaching: An emerging family science field. Family Relations, 63(5), 569-582.

Bakker, A. B., \& Schaufeli, W. B. (2008). Positive organizational behavior: Engaged employees in flourishing organizations. Journal of Organizational Behavior, 29(2), 147-154.

Bas, A. U., \& Firat, N. S. (2017). The Views and Opinions of School Principals and Teachers on Positive Education. Journal of Education and Training Studies, 5(2), 85-92.

Biswas-Diener, R., \& Dean, B. (2010). Positive Psychology Coaching: Putting the Science of Happiness to Work for your Clients. New York: John Wiley \& Sons.

Bourdieu, P. (1986). The forms of capital. In J. G. Richardson (Ed.), Handbook of Theory and Research for the Sociology of Education (pp. 241-258). New York: Greenwood.

Braun, V., \& Clarke, V. (2006). Using thematic analysis in psychology. Qualitative Research in Psychology, 3(2), 77-101. doi: 10.1191/1478088706qp063oa

Cameron, K. S., Dutton, J. E., \& Quinn, R. E. (Eds.). (2003). Positive organizational scholarship: Foundations of a new discipline. San Francisco: Berrett-Koehler.

Collier, J., \& Collier, M. (1986). Visual Anthropology: Photography as a Research Method. Albuquerque, NM: 
University of New Mexico.

Csikszentmihalyi, M. (1990). Flow: The Psychology of Optimal Experience. New York: Harper Perennial.

de Chavez, A. C., Backett-Milburn, K., Parry, O., \& Platt, S. (2005). Understanding and researching wellbeing: Its usage in different disciplines and potential for health research and health promotion. Health Education Journal, 64(1), 70-87. doi: 10.1177/001789690506400108

Deci, E. L., \& Ryan, R. M. (1980). Self-determination Theory: When Mind Mediates Behavior. The Journal of Mind and Behavior, 33-43.

Deci, E. L., \& Vansteenkiste, M. (2004). Self-determination theory and basic need satisfaction: Understanding human development in positive psychology. Ricerche di psicologia.

Diener, E. (2000). Subjective well-being: The science of happiness and a proposal for a national index. American Psychologist, 55(1), 34-43. doi: 10.1037/0003-066X.55.1.34

Emmons, R. A., \& McCullough, M. E. (2003). Counting blessings versus burdens: An experimental investigation of gratitude and subjective well-being in daily life. Journal of Personality and Social Psychology, 84(2), 377-389.

Fredrickson, B. (2009). Positivity: Groundbreaking Research Reveals how to Embrace the Hidden Strength of Positive Emotions, Overcome Negativity, and Thrive. USA: Crown Publisher.

Gaylord, E. C. (1967). Modern Coaching Psychology. Iowa: W.C. Brown Book Company.

Gorby, C. B. (1937). Everyone gets a share of the profits. Factory Management E Maintenance, 95, 82-83.

Grant, A. M., \& Cavanagh, M. J. (2007). Evidence-based coaching: Flourishing or languishing? Australian Psychologist, 42(4), 239-254.

Grant, A. M., \& Palmer, S. (2002). Coaching psychology workshop. Paper presented at the Annual Conference of the Counselling Psychology Division of the BPS, Torquay.

Griffith, C. R. (1926). Psychology of coaching: A study of coaching methods from the point of view of psychology. New York: Charles Scribner's Sons.

Haidt, J., Rosenberg, E., \& Hom, H. (2003). Differentiating diversities: Moral diversity is not like other kinds. Journal of Applied Social Psychology, 33(1), 1-36.

Ivtzan, I., \& Lomas, T. (Eds.). (2016). Mindfulness in Positive Psychology: The Science of Meditation and Wellbeing. London: Routledge.

Jackson, S. A., \& Csikszentmihalyi, M. (1999). Flow in sports: The keys to optimal experiences and performances. Champaign, IL: Human Kinetics Books.

Kabat-Zinn, J. (1982). An outpatient program in behavioral medicine for chronic pain patients based on the practice of mindfulness meditation: Theoretical considerations and preliminary results. General Hospital Psychiatry, 4(1), 33-47. doi: 10.1016/0163-8343(82)90026-3

Kampa-Kokesch, S., \& Anderson, M. Z. (2001). Executive coaching: A comprehensive review of the literature. Consulting Psychology Journal: Practice and Research, 53(4), 205-228. doi: 10.1037/10614087.53.4.205

Kauffman, C. (2006). Positive psychology: The science at the heart of coaching. In S. DR \& G. AM (Eds.), Evidence based coaching handbook: Putting best practices to work for your clients (pp. 219-253). Hoboken, NJ: Wiley.

Kearney, K. S., \& Hyle, A. E. (2004). Drawing out emotions: The use of participant-produced drawings in qualitative inquiry. Qualitative Research, 4(3), 361-382. doi: 10.1177/1468794104047234

Keyes, C. L. M. (2002). The mental health continuum: From languishing to flourishing in life. Journal of Health and Social Behavior, 43(2), 207-222. doi: 10.2307/3090197

Larson, J. S. (1999). The conceptualization of health. Medical Care Research and Review, 56(2), 123-136. doi: $10.1177 / 107755879905600201$

Lawther, J. D. (1951). Psychology of Coaching. Oxford: Prentice-Hall.

Linley, P. A., \& Harrington, S. (2007). Integrating positive psychology and coaching psychology: Shared assumptions and aspirations? In S. Palmer \& A. Whybrow (Eds.), The Handbook of Coaching Psychology (pp. 86-117). London: Routledge.

Linley, P. A., \& Joseph, S. (2004). Applied positive psychology: A new perspective for professional practice. In P. A. Linley \& S. Joseph (Eds.), Positive Psychology in Practice (pp. 3-12). Hoboken, New Jersey: John Wiley and Sons. 
Linley, P. A., Nielsen, K. M., Gillett, R., \& Biswas-Diener, R. (2010). Using signature strengths in pursuit of goals: Effects on goal progress, need satisfaction, and well-being, and implications for coaching psychologists. International Coaching Psychology Review, 5(1), 6-15.

Lomas, T. (2015a). Positive cross-cultural psychology: Exploring similarity and difference in constructions and experiences of wellbeing. International Journal of Wellbeing, 5(4), 60-77. doi: 10.5502/ijw.v5i4.3

Lomas, T. (2015b). Positive social psychology: A multilevel inquiry into socio-cultural wellbeing initiatives. Psychology, Public Policy, and Law, 21(3), 338-347. doi: 10.1037/law0000051

Lomas, T. (2016). Positive art: Artistic expression and appreciation as an exemplary vehicle for flourishing. Review of General Psychology, 20(2), 171-182. doi: 10.1037/gpr0000073

Lomas, T. (2017). Recontextualising mindfulness: Theravada Buddhist perspectives on the ethical and spiritual dimensions of awareness. Psychology of Religion and Spirituality, Vol 9(2), 209-219. doi: 10.1037/rel0000080

Lomas, T., Hefferon, K., \& Ivtzan, I. (2015). The LIFE model: A meta-theoretical conceptual map for applied positive psychology. Journal of Happiness Studies, 16(5), 1347-1364. doi: 10.1007/s10902-014-9563-y

Lomas, T., \& Ivtzan, I. (2016a). Professionalising positive psychology: Developing guidelines for training and regulation. International Journal of Wellbeing, 6(3), 96-112. doi: 10.5502/ijw.v6i3.4

Lomas, T., \& Ivtzan, I. (2016b). Second wave positive psychology: Exploring the positive-negative dialectics of wellbeing. Journal of Happiness Studies, 17(4), 1753-1768. doi: 10.1007/s10902-015-9668-y

Luthans, F., Avolio, B. J., Avey, J. B., \& Norman, S. M. (2007). Positive psychological capital: Measurement and relationship with performance and satisfaction. Personnel Psychology, 60(3), 541-572.

McNulty, J. K., \& Fincham, F. D. (2011). Beyond positive psychology? Toward a contextual view of psychological processes and well-being. American Psychologist, 67(2), 101-110.

Oades, L., \& Passmore, J. (2014). Positive psychology coaching. In J. Passmore (Ed.), Mastery in Coaching (pp. 15-40). London: Kegan Page.

Palmer, S., \& Whybrow, A. (2014). Handbook of coaching psychology: A guide for practitioners. London: Routledge.

Passmore, J., \& Marianetti, O. (2007). The role of mindfulness in coaching. The Coaching Psychologist, 3(3), 131-137.

Passmore, J., \& Oades, L. (2014). Positive psychology coaching. The Coaching Psychologist, 10(2), 68-70.

Passmore, J., \& Theeboom, T. (2016). Coaching psychology research: A journey of development. In L. E. Van Zyl, M. W. Stander \& A. Odendaal (Eds.), Coaching Psychology: Meta-theoretical perspectives and applications in multicultural contexts (pp. 27-46). Netherlands: Springer.

Pawelski, J. O. (2016a). Defining the 'positive' in positive psychology: Part I. A descriptive analysis. The Journal of Positive Psychology, 11(4), 339-356. doi: 10.1080/17439760.2015.1137627

Pawelski, J. O. (2016b). Defining the 'positive' in positive psychology: Part II. A normative analysis. The Journal of Positive Psychology, 11(4), 357-365. doi: 10.1080/17439760.2015.1137628

Pollard, E. L., \& Davidson, L. (2001). Foundations of Child Wellbeing. Paris: UNESCO.

Proctor, C., Maltby, J., \& Linley, P. A. (2011). Strengths use as a predictor of well-being and health-related quality of life. Journal of Happiness Studies, 12(1), 153-169.

Randolph, J. (2015). Positive Neuropsychology: A Framework for Cognitive Health. Editor's Corner, 29(2), 25.

Ryan, R. M., \& Deci, E. L. (2000). Self-determination theory and the facilitation of intrinsic motivation, social development, and well-being. American Psychologist, 55(1), 68-78. doi: 10.1037/0003-066X.55.1.68

Ryan, R. M., Huta, V., \& Deci, E. L. (2013). Living well: A self-determination theory perspective on eudaimonia. In A. Delle Fave (Ed.), The Exploration of Happiness (pp. 117-139). Dordrecht: Springer.

Salama-Younes, M. (2011). Towards a positive sport psychology: A prospective investigation in physical practice. World Journal of Sport Sciences, 4(2), 104-115.

Schmidt, C. K., Raque-Bogdan, T. L., Piontkowski, S., \& Schaefer, K. L. (2011). Putting the positive in health psychology: A content analysis of three journals. Journal of Health Psychology, 16(4), 607-620.

Seligman, M. E. P. (1999). Positive social science. Journal of Positive Behavior Interventions, 1(3), 181-182.

Seligman, M. E. P. (2008). Positive health. Applied Psychology, 57, 3-18. doi: 10.1111/j.1464-0597.2008.00351.x

Seligman, M. E. P. (2012). Flourish: A Visionary New Understanding of Happiness and Well-being. New York: 
Simon and Schuster.

Seligman, M. E. P., Ernst, R. M., Gillham, J., Reivich, K., \& Linkins, M. (2009). Positive education: Positive psychology and classroom interventions. Oxford Review of Education, 35(3), 293-311. doi: 10.1080/03054980902934563

Seligman, M. E. P., Rashid, T., \& Parks, A. C. (2006). Positive psychotherapy. American Psychologist, 61(8), 774-788. doi: 10.1037/0003-066X.61.8.774

Spence, G. B. (2007). Further development of evidence-based coaching: Lessons from the rise and fall of the human potential movement. Australian Psychologist, 42(4), 255-265.

Spence, G. B., \& Oades, L. G. (2011). Coaching with self-determination theory in mind: Using theory to advance evidence-based coaching practice. International Journal of Evidence-Based Coaching and Mentoring, 9(2), 37-55.

Tang, Y.-Y., Ma, Y., Wang, J., Fan, Y., Feng, S., Lu, Q., . . . Posner, M. I. (2007). Short-term meditation training improves attention and self-regulation. Proceedings of the National Academy of Sciences, 104(43), 17152-17156. doi: 10.1073/pnas.0707678104

Urry, H. L., Nitschke, J. B., Dolski, I., Jackson, D. C., Dalton, K. M., Mueller, C. J., . . Davidson, R. J. (2004). Making a life worth living: Neural correlates of well-being. Psychological Science, 15(6), 367-372. doi: 10.1111/j.0956-7976.2004.00686.x

van Nieuwerburgh, C., \& Tunariu, A. (2013). Responding to a new landscape: Towards integrative practice. Coaching Today, 8, 6-10.

Waterman, A. S. (2013). The humanistic psychology-positive psychology divide: Contrasts in philosophical foundations. American Psychologist, 68(3), 124-133. doi: 10.1037/a0032168

Waters, L. (2014). Balancing the curriculum: Teaching gratitude, hope and resilience A love of Ideas (pp. 117124). Melbourne, Australia: Future Ideas.

Waters, T. E. A. (2014). "Relations between the functions of autobiographical memory and psychological wellbeing." Memory, 22 (3), 265-275.

White, M. A., \& Waters, L. E. (2015). A case study of 'The Good School:' Examples of the use of Peterson's strengths-based approach with students. The Journal of Positive Psychology, 10(1), 69-76. doi: 10.1080/17439760.2014.920408

Wilkinson, R. A., \& Chilton, G. (2013). Positive art therapy: Linking positive psychology to art therapy theory, practice, and research. Art Therapy, 30(1), 4-11. doi: 10.1080/07421656.2013.757513

Wood, A. M., \& Tarrier, N. (2010). Positive Clinical Psychology: A new vision and strategy for integrated research and practice. Clinical Psychology Review, 30(7), 819-829. doi: http://dx.doi.org/10.1016/j.cpr.2010.06.003

Young, H., Miyamoto, S., Ward, D., Dharmar, M., Tang-Feldman, Y., \& Berglund, L. (2014). Sustained effects of a nurse coaching intervention via telehealth to improve health behavior change in diabetes. Telemedicine and e-Health, 20(9), 828-834. 